\title{
IMPLEMENTASI SISTEM OTENTIKASI \\ PADA PENGGUNA JARINGAN HOTSPOT GUNA MENINGKATKAN KEAMANAN JARINGAN KOMPUTER
}

\author{
Oleh: Irma T \\ Pendidikan Matematika IAIN Palopo \\ e-mail: irmailkom@yahoo.co.id
}

\begin{abstract}
Abstrak:
Semakin banyaknya aplikasi yang menggunakan client server baik desktop maupun WEB Application membuat setiap user harus memiliki banyak user id dan password yang harus dihapalkan, karena setiap aplikasi pasti membutuhkan otentikasi agar dapat memanfaatkan aplikasi tersebut dengan alasan keamanan. Selain itu perkembangan media jaringan juga semakin berkembang baik penggunaan kabel maupun nirkabel. Dari penjelasan diatas teknologi RADIUS sangatlah dibutuhkan dalam kasus yang telah dijelaskan diatas, karena dengan metode RADIUS ini memungkinkan seorang user cukup memiliki satu user id untuk mengakses ke beberapa aplikasi, baik desktop maupun WEB application. Metode RADIUS juga dapat diintregasikan terhadap media kabel dan nirkabel.
\end{abstract}

Kata kunci: Nirkabel, WEP, otentikasi, RADIUS, database, server, client

\section{Pendahuluan}

Penggunaan jaringan saat ini pada umumnya tanpa adanya otentikasi pengguna. Dengan tanpa adanya otentikasi pengguna ini maka jaringan dapat diakses oleh siapa saja ketika pengguna bergabung dalam jaringan. Untuk media transmisi menggunakan wireless access point otentikasi menggunakan Wired Equivalent Privacy (WEP). Key pada WEP harus dipasang pada tiap access point dan tiap client access point, sehingga merepotkan administrator karena harus mendatangi masing-masing client. Key WEP juga bersifat statik sehingga mudah diketahui dengan melihat komputer client yang lain. Sekarang sudah ada beberapa aplikasi yang bisa membaca key WEP sehingga pengguna yang tidak berhak bias masuk ke jaringan, yang bisa membahayakan sistem didalamnya. Otentikasi WEP hanya diberikan kepada jalur koneksi untuk staf, sedangkan jalur koneksi untukmahasiswa (hostspot) yang menggunakan mediatransmisi wireless access point tanpa menggunakanotentikasi sehingga dapat diakses oleh siapa saja. 
Padamedia transmisi kabel yang menggunakan HUB sebagai pemecah koneksi tidak menggunakan otentikasi, sehingga dengan menancapkan kabel kita bisa langsung terhubung ke jaringan. Oleh karena itu dalam penelitian ini dibuat sistem untuk otentikasi pengguna, baik yang menggunakan media transmisi kabel maupun nirkabel.

Dalam artikel ini akan diketahui bagaimana pengembangan manajemen sistem keamanan jaringan yang lebih baik, serta mengintregasikan manajemen user untuk beberapa aplikasi

\section{Mode Jaringan dan Protokol Route}

Jaringan Wireless Jaringan Wireless Local Area Network (WLAN) merupakan salah satu bentuk jaringan wireless. Jaringan WLAN adalah jaringan yang memungkinkan dua mesin atau lebih untuk berkomunikasi menggunakan protokol jaringan standar tetapi tanpa menggunakan media transmisi kabel. Media transmisi yang digunakan komunikasi pada jaringan WLAN adalah gelombang elektromagnetik yang dapat berupa sinar infra-merah (infrared, IR), gelombang mikro (microwave) atau gelombang radio (radio frequency, RF). Mode Jaringan WLAN, antara lain:

\section{Mode Ad-Hoc}

Mode Ad-hoc sering disebut sebagai jaringan peer to peer atau disebut juga jaringan point to point. Mode Ad-hoc memungkinkan hubungan antar computer pada jaringan WLAN tanpa melalui suatu access point.

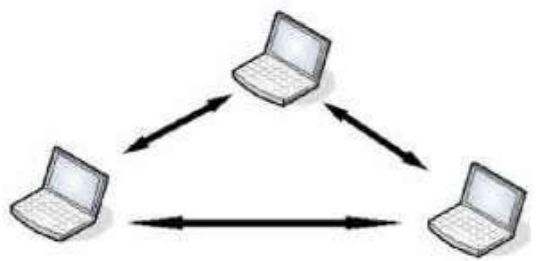

Gambar 1. Mode Ad-hoc

\section{Mode Infrastruktur}

Untuk menghubungkan banyak computer jaringan WLAN harus dijalankan menggunakan mode Infrastruktur. Pada mode Infrastruktur diperlukan peralatan tambahan berupa wireless access point (WAP) atau disebut secara singkat dengan access point. Access point berlaku seperti HUB atau switch pada jaringan kabel, sehingga access point akan menjadi pusat dari jaringan WLAN. 


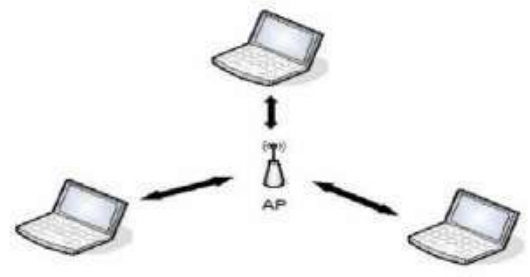

Gambar 2. Mode Infrastruktur

Jaringan WLAN yang bekerja pada mode Infrastruktur dapat dihubungkan dengan jaringan lain misalnya jaringan Ethernet. Untuk berhubungan dengan jaringan lain diperlukan bridge. Access point yang beredar di pasaran umumnya sudah dapat difungsikan sebagai bridge.

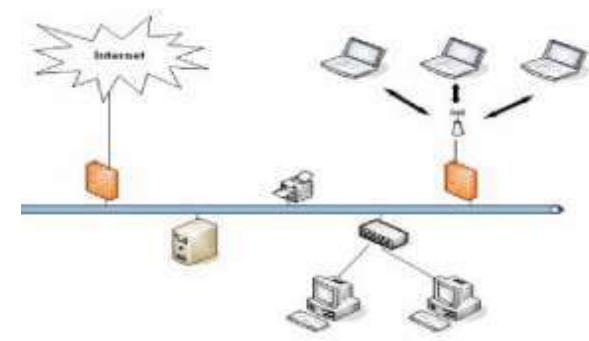

Gambar 3. Jaringan WLAN dan Ethernet

Routing adalah proses membawa paket data dari satu host asal ke host tujuan melalui satu atau beberapa host node lainnya. Secara umum mekanisme koordinasi routing dapat dibagi menjadi dua, yaitu routing statis dan routing dinamis, dengan penjelasan sebagai berikut:

\section{Routing Statis}

Pada routing statis, entri-entri dalam forwarding tabel routing diisi dan dihapus secara manual sedangkan pada routing dinamis perubahan dilakukan melalui protokol routing. Routing statis adalah pengaturan routing paling sederhana yang dapat dilakukan pada jaringan komputer. Menggunakan routing statis murni dalam sebuah jaringan berarti mengisi setiap entri dalam forwarding table di setiap router yang berada dalam jaringan tersebut. 
Penggunaan routing statis dalam sebuah jaringan yang kecil bukanlah sebuah masalah hanya beberapa entri yang perlu diisikan pada forwarding table di setiap router. Sebaliknya jika harus melengkapi forwarding table di setiap router yang jumlahnya tidak sedikit dalam jaringan yang besar.

\section{Routing Dinamis}

Routing dinamis adalah cara yang digunakan untuk melepaskan kewajiban mengisi entri-entri forwarding table secara manual. Protokol routing mengatur router-router sehingga dapat berkomunikasi satu dengan yang lain dan saling memberikan informasi routing yang dapat mengubah isi forwarding table, tergantung keadaan jaringannya. Dengan cara ini, router-router mengetahui keadaan jaringan yang terakhir dan mampu meneruskan datagram ke arah yang benar.

RADIUS adalah sebuah protokol keamanan komputer yang digunakan untuk melakukan otentikasi, otorisasi, dan pendaftaran akun pengguna secara terpusat untuk mengakses jaringan. RADIUS didefinisikan di dalam RFC 2865 dan RFC 2866, yang pada awalnya digunakan untuk melakukan otentikasi terhadap akses jaringan secara jarak jauh dengan menggunakan koneksi dial-up. RADIUS, kini telah diimplementasikan untuk melakukan otentikasi terhadap akses jaringan secara jarak jauh dengan menggunakan koneksi selain dial-up, seperti halnya VPN (Virtual Private Networking), access point nirkabel, switch Ethernet, dan perangkat lainnya.

Server RADIUS menyediakan mekanisme keamanan dengan menangani otentikasi dan otorisasi koneksi yang dilakukan pengguna. Pada saat computer client akan menghubungkan diri dengan jaringan maka server RADIUS akan meminta identitas pengguna (username dan password) untuk kemudian dicocokkan dengan data yang ada dalam database server RADIUS untuk kemudian ditentukan apakah pengguna diijinkan untuk menggunakan layanan dalam jaringan komputer. Jika proses otentikasi dan otorisasi berhasil maka proses pelaporan dilakukan, yakni dengan mencatat semua aktifitaskoneksi pengguna, menghitung durasi waktu dan jumlah transfer data yang dilakukan oleh pengguna. Proses pelaporan yang dilakukan server RADIUS bisa dalam bentuk waktu (detik, menit, jam) maupun dalam bentuk besar transfer data (Byte, KByte, Mbyte). 
87 | al-Khwarizmi, Volume III, Edisi 2, Oktober 2015, Hal. 83 - 92

WEP (Wired Equivalent Privacy) adalah suatumetode pengamanan jaringan nirkabel, disebut juga dengan Shared Key Authentication. Shared Key Authentication adalah metode otentikasi yang membutuhkan penggunaan WEP. Enkripsi WEP menggunakan kunci yang dimasukkan (oleh administrator) ke client maupun access point. Kunci ini harus cocok dari yang diberikan akses point ke client, dengan yang dimasukkan client untuk otentikasi menuju access point.

\section{Rancang Sistem}

Perangkat Keras (Minimal) yang dibutuhkan adalah sebagai berikut:

1. Motherboard x86 $300 \mathrm{MHZ}$ Pentium

2. RAM $64 \mathrm{MB}$

3. Hardisk $40 \mathrm{~GB}$

Kebutuhan hardware untuk menginstal Router OS, dalam hal ini menggunakan MikrotikOS

1. CPU dan motherboard $100 \mathrm{MHz}$ Pentium.

2. RAM $32 \mathrm{MB}$

3. Hardisk ATA/IDE 1 GB.

Media instalasi Linux Ubuntu dan MikroTik adalah:

1. CD Linux Ubuntu Server 8.04 LTS

2. CD MikroTik

3. Software FreeRADIUS Server

4. Software LAMP (Linux Apache MySql Php)

Pada dasarnya, Pengguna melihat bahwa jaringan yang diperlukan cukup sederhana dan tidak rumit. Ini dikarenakan client memandang jaringan hanya digunakan untuk share informasi yang umum dan koneksi internet.

Aplikasi Desktop adalah suatu aplikasi yang dapat berjalan sendiri atau independen tanpa menggunakan browser pada suatu komputer otonom dengan sistem operasi tertentu. Penggunaan aplikasi desktop dengan cara meng-install aplikasi ini pada masingmasing pengguna. Penggunaan aplikasi desktop untuk proses administrasi.

Beberapa aplikasi berbasis WEB yang ada di laboratorium dapat mengakses aplikasi desktop dan elearning, aplikasi WEB, sedangkan hostspot hanya mengakses ebook, ejournal, WEB mail client, aplikasi WEB saja. line, SIAKAD yang bisa diakses baik melalui jaringan lokal maupun jaringan internet.

Perancangan Sistem 
Beberapa aplikasi server yang digunakan di WEB server pada database server, mail server, FTP server, DNS server, proxy server dan firewall.

Untuk administrasi dan akses internet. Untuk menghubungkan antar gedung kabel yang digunakan adalah kabel STP (Shield Twister Pair). Untuk menghubungkan client dalam satu ruangan digunakan media transmisi kabel UTP (Unshield Twister Pair) dan wireless. Sedang-kan media transmisi untuk hostspot area Untuk memecah antar client digunakan HUB yang diletakan ditiap gedung atau ruangan disesuai- kan dengan jumlah client.

Secara sederhana desain topologi dengan RADIUS Server. Server RADIUS berfungsi menyimpan username dan password secara terpusat. Pengguna memasukan username dan password melalui interface yang disediakan oleh NAS (Network Access Server), selanjutnya NAS akan menanyakan ke RADIUS server apakah username dan password ada dalam database. Jika username dan password ada maka pengguna akan diijinkan menggunakan jaringan.

Arsitektur sistem otentikasi seperti terlihat pada menggambarkan arsitektur sistem otentikasi, terlihat bahwa pengguna agar terhubung ke dalam jaringan harus menggunkan PC atau Laptop. Pengguna dapat memanfaatkan jaringan apabila memiliki username dan password pada RADIUS server. Apabila pengguna sudah berhasil login, maka pengguna bisa terhubung kejaringan. Username dan password yang digunakan untuk login adalah user dan password yang digunakan untuk login pada aplikasi bits.

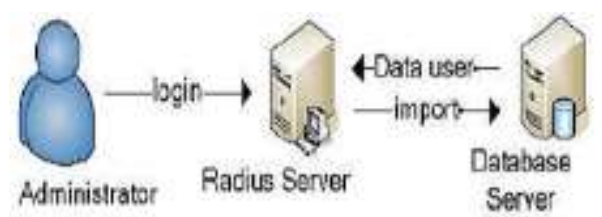

Gambar 4. Arsitektur pengambilan Data Pengguna 
89 | al-Khwarizmi, Volume III, Edisi 2, Oktober 2015, Hal. 83 - 92

Pengujian Hasil Tool Importer Pengguna

\begin{tabular}{|c|c|c|c|}
\hline $\begin{array}{l}\text { Tent II } \\
\text { Tajuas Tet } \\
\text { Meadis Anel }\end{array}$ & & 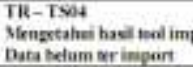 & \\
\hline Prestarpenzujian & Hsoull yasg dihuraplati & IEatlyain digenikh & Kevimpilan \\
\hline \multicolumn{4}{|c|}{ Data bertane di impert } \\
\hline 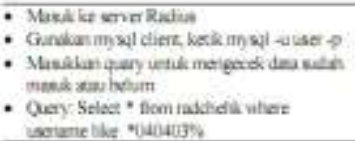 & 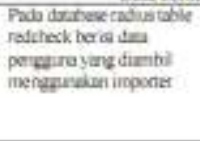 & 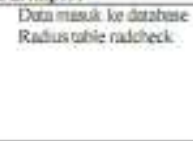 & $\begin{array}{l}\text { Towl inponer bejaly } \\
\text { esati derges } \\
\text { ancoryen }\end{array}$ \\
\hline
\end{tabular}

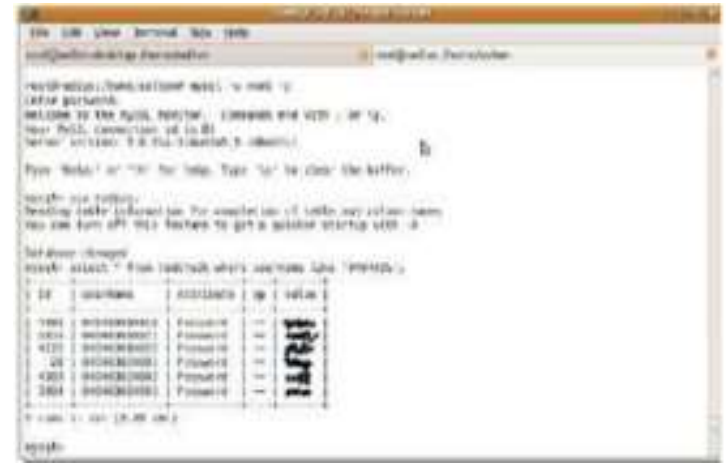

Gambar 5. RedCheck

\begin{tabular}{|c|c|c|c|}
\hline $\begin{array}{l}\text { Ted in } \\
\text { Totman Test }\end{array}$ & & \multicolumn{2}{|c|}{ 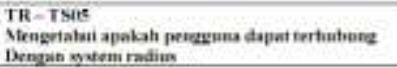 } \\
\hline humatid An al & \multicolumn{3}{|c|}{ Perchgana ratlius haseag } \\
\hline Fresndur peugujian & Ilusidl yatug diharapkatu & Ihas yatrt dipernieh & Koimpuinh \\
\hline \multicolumn{4}{|c|}{ Iserpadius bieuted } \\
\hline 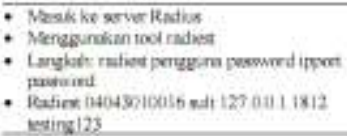 & 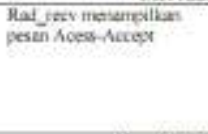 & $\begin{array}{l}\text { Red_fosv itietatipisan } \\
\text { pesin Acess-Recepk }\end{array}$ & 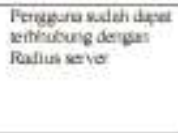 \\
\hline \multicolumn{4}{|c|}{ Lur nidek bist verhubarz } \\
\hline 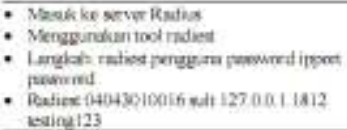 & 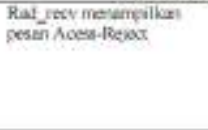 & $\begin{array}{l}\text { Rad_fes mercuprivan } \\
\text { peuxs Acess-Rejest }\end{array}$ & 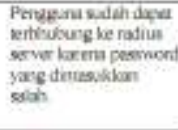 \\
\hline
\end{tabular}

Gambar 6. Pengujian Pengguna 
Implementasi Sistem Otentikasi ...| 90

\begin{tabular}{|c|c|c|c|}
\hline $\begin{array}{l}\text { Test III } \\
\text { Tequan Test } \\
\text { Kindid inal }\end{array}$ & & $\begin{array}{l}\text { TR-TSil } \\
\text { Mengetahui fungsi wer I } \\
\text { Isertidak ada }\end{array}$ & Mikrocik Nas \\
\hline Prosedur pengujian & Hasidil yang Giharaphan & Had yang diperileh & Keverpulan \\
\hline \multicolumn{4}{|c|}{ Iser flisuble pada Nilirutik } \\
\hline 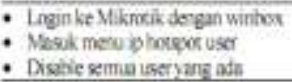 & Ler cepar meizaban logn & $\begin{array}{l}\text { Uer apet ineswing } \\
\text { legin }\end{array}$ & $\begin{array}{l}\text { Kanurikas Mikrotik } \\
\text { NAS bejalan dergan } \\
\text { nomnd }\end{array}$ \\
\hline \multicolumn{4}{|c|}{ Tser AhI pads Mhrutik Mes } \\
\hline 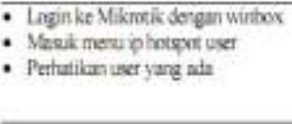 & $\begin{array}{l}\text { Lis pergegra mucul paly } \\
\text { tubative }\end{array}$ & $\begin{array}{l}\text { Lis pengenatmurcel } \\
\text { podntabactuve }\end{array}$ & 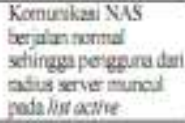 \\
\hline
\end{tabular}

\section{Gambar 7. Pengujian Mikrotik HotsPot User}

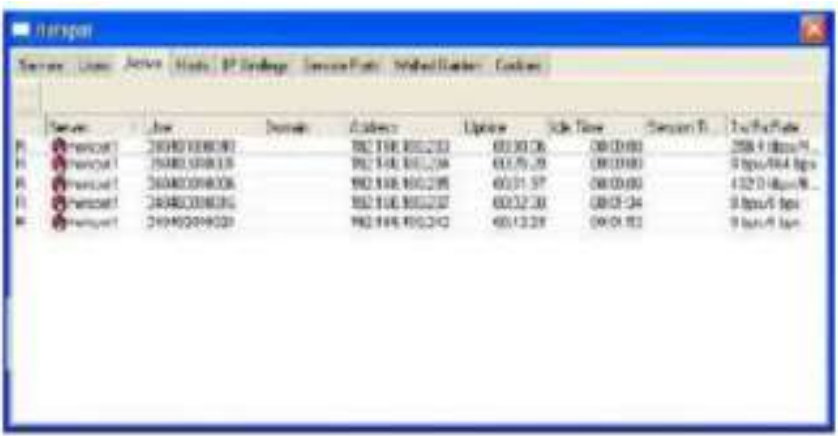

Gambar 8. User Aktif Pengguna Jaringan

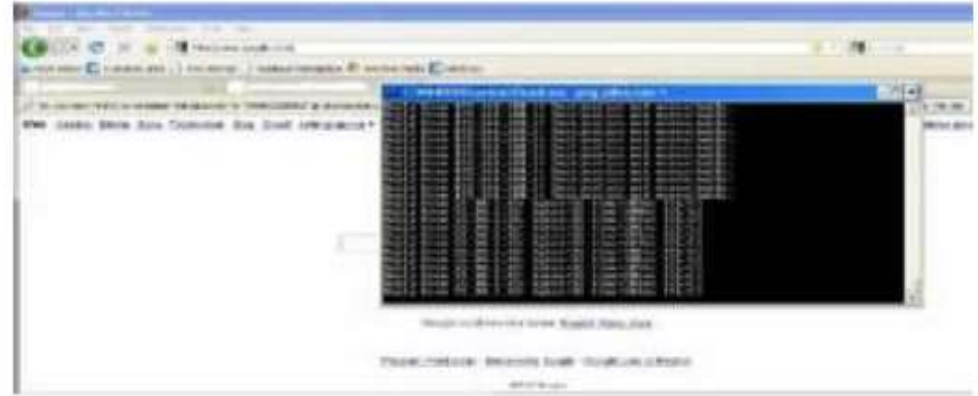

Gambar 9. Uji Coba Login Sukses 
91 | al-Khwarizmi, Volume III, Edisi 2, Oktober 2015, Hal. 83 - 92

IV. Kesimpulan

Berdasarkan pengujian dan implementasi system yang telah dilakukan, dapat disimpulkan bahwa dengan menggunakan RADIUS dengan software free RADIUS yang dihubungkan dengan Mikrotik sebagai network access server dapat digunakan untuk otenti- kasi pengguna pada jaringan Dengan adanya otentikasi user ini diharapkan dapat meningkatkan keamanan jaringan komputer. 


\section{DAFTAR PUSTAKA}

Implementasi Sistem Otentikasi ...| 92

Arifin, Zaenal. 2008. Sistem Pengamanan Jaringan Wireless LAN Berbasis Protokol 8.02.1x dan Sertfikat. Penerbit Andi. Yogyakarta.

Febyatmoko, dkk. 2006. Otentikasi, Otorisasi \& Pelaporan Koneksi User Wireless Chillispot dan Server RADIUS. http://journal.uii.ac.id/index.php/ mediainformat ika/ article/viewFile/122/83 (akses 20 januari 2010).

Kelompok 123P IKI-83408T MTI UI. 2005. Keamanan Jaringan Komputer. http://bebas.vlsm. org/v06/Kuliah/MTIKeamananSistem-Informasi/ 2005/123/123P-03-final1.0-network_security.pdf (akses 20 januari 2010).

Linto, Herlambang Moch., dan Catur L. Azis. 2008. Panduan Lengkap Menguasai Router Masa Depan Menggunakan Mikrotik RouterOSTM. Penerbit Andi. Yogyakarta.

Rigney, et al. 2000. Remote Authentication Dial In User Service (RADIUS). http://www.ietf.org/rfc/ rfc2865.txt (akses 19 januari 2010).

Wagito. 2007. Jaringan Komputer Teori dan Implementasi Berbasis Linux. Gava Media. Yogyakarta. 